\title{
lleitis - do endoscopist and pathologist speak the same language?
}

\author{
Leticia ROSEVICS, Luiz Roberto KOTZE and Odery RAMOS JÚNIOR
}

Received: 21 June 2020

Accepted: 30 January 2021

\begin{abstract}
Background - Ileitis is defined as an inflammation of the ileum, which is evaluated during colonoscopy. Biopsies should be performed on altered ileus, aiding to the diagnosis. Objective - Evaluate the correlation of anatomopathological findings on ileitis between pathologists and endoscopists. Methods - A retrospective, cross-sectional study, between 2013 and 2017. Examination report, indications for colonoscopy, and medical records were evaluated to identify whether the colonoscopic findings were clinically significant. Anatomopathological samples were reviewed by a pathologist expert in gastrointestinal tract. Patients over 18 years of age who had undergone ileoscopy were included, whereas patients below 18 years of age and those with previous intestinal resections were excluded. The correlation was assessed using the kappa coefficient index. Results - A total of 5833 colonoscopies were conducted in the study period and 3880 cases were included. Ileal alterations were observed in 206 cases, with $2.94 \%$ being clinically significant. A hundred and sixty three biopsies were evaluated using the kappa index, resulting in agreement among pathologists of 0.067 and among pathologist and endoscopist of 0.141. Conclusion - It was observed that despite the low concordance between pathologists and endoscopists, there was no change in patient outcomes. This study confirms the importance of knowledge of the main anatomopathological changes related to ileitis by pathologists and endoscopists, making the best diagnosis and follow-up.
\end{abstract}

Keywords - Colonoscopy; ileitis, inflammatory bowel disease; gastrointestinal pathology.

\section{INTRODUCTION}

Ileitis is defined as an inflammation of the ileum, which is the portion of the small intestine that is evaluated during colonoscopy $^{(1)}$. Although ileoscopy with biopsy is frequently practiced, there is small data in the literature about its histopathological relevance and clinical management. The exception is made in cases of differential diagnosis of diarrhea, in which the validity of the ileum assessment is well established ${ }^{(2-5)}$.

Although Crohn's disease is commonly associated with ileitis, other differential diagnoses must be considered on this clinical presentation. These diagnoses can be divided into the following etiologic groups: infectious diseases, such as tuberculosis and cytomegalovirus infection; spondyloarthropathy, as an example ileitis related to ankylosing spondylitis; vasculitis; neoplasms, for instance carcinoid tumor; drug-induced, related to non-steroidal anti-inflammatories and hydrochlorothiazide; systemic diseases; lymphoid hyperplasia; and immunoglobulin-G4-related disease ${ }^{(1,6-11)}$.

The assessment of the ileum is part of the complete colonoscopy, however due to the difficulty in carrying it out, which increases the examination time, and to the fact that it does not bring new information for the diagnosis in most cases, its performance in all colonoscopies has been questioned ${ }^{(4,5,7,12)}$. Therefore, it is likely that its relevance is greater in symptomatic patients ${ }^{(13)}$.

The aim of this study is to assess the agreement between endoscopists and pathologists when ileitis is endoscopically found and thus to estimate the importance of the ileal evaluation.

\section{METHODS}

This study was conducted retrospectively using the data of colonoscopy examinations performed at the Clinical Hospital of the Federal University of Paraná, a Brazilian tertiary public university hospital, between 2013 and 2017.

The study sample was made in phases, as follow:

- Colonoscopies selection: patients over 18 years of age who underwent ileoscopy, without previous gastrointestinal surgical manipulation, were included. Colonoscopic examinations performed on patients under 18 years of age, without ileal evaluation or who had undergone surgical manipulation with total or partial resection of the small and/or large intestines, were excluded.

- Criteria for ileitis: colonoscopy reports of selected patients were reviewed, and were included patients with described ileitis ileal changes described by the endoscopist.

- Review of biopsy slides: the composition of the number of slides reviewed included all ileitis who had undergone biopsy. Patients with ileitis but no biopsy and those in which biopsy material were not found in the hospital files were excluded.

The indications of colonoscopy were categorized as the following: abdominal pain, follow-up of patients with inflammatory bowel disease (IBD), bleeding from the gastrointestinal tract, constipation, diarrhea, chronic anemia, weight loss / consumptive disease, change in bowel habit, control of neoplasia of the gastrointestinal tract, control of colonic polyps, colorectal cancer screening, and others.

Declared conflict of interest of all authors: none

Disclosure of funding: no funding received

Universidade Federal do Paraná, Hospital de Clínicas, Curitiba, PR, Brasil.

Corresponding author: Leticia Rosevics. E-mail: le.rosevics@yahoo.com.br 
The characterization of ileitis included ileal changes that could be described in the ileocolonoscopy exam such as erosion, ulcer, lymphoid hyperplasia, enanthema, polyps and others, for example stenosis and friability.

Each case was evaluated by reviewing both the original pathology report and consultant gastrointestinal pathologist. All pathology slides were reviewed by a pathologist expert in the gastrointestinal tract, who had access, prior to the analysis, to the same information as the colleague (request for anatomopathology issued by the endoscopist who performed the exam). The data collected included the ileal anatomopathological alterations classified as: ulcer, erosion, acute ileitis, chronic ileitis, normal ileum, lymphoid hyperplasia, viral inclusion, and others.

In order to assess whether the ileitis was clinically relevant, as well as the disagreement between pathologists, a review of the medical records of patients was performed evaluating their follow-up and outcomes. When the presence of ileitis indicates a diagnostic or therapeutic change, it was considered clinically significant.

To characterize the agreement between pathologist and endoscopist, the presence of the elementary injury described in colonoscopy was compared to the histopathological description (erosion, ulcers, lymphoid hyperplasia, polyps). To assess the agreement between pathologists, it were compared the anatomopathological description reports.

The results obtained in the study were represented as mean, standard deviation, minimum and maximum values (for age), or by frequencies and percentages (categorical variables). The evaluation of correlation between pathological reports and endoscopic exams were described using the percentiles and they were compared using the kappa coefficient by the computer program SPSS version 22.0 (IBM).

The study was submitted and approved by the Research Ethics Committee of the Clinical Hospital of University Federal of Paraná.

\section{RESULTS}

From 2013 to 2017, 5833 colonoscopies were performed at our hospital, from which 3880 were included in this study. There were 206 reports of ileitis $(5.31 \%)$, and 163 cases underwent histological review.

From all 206 diagnosis of ileitis, the medical records were reviewed to assess whether the ileitis was clinically significant, that is, cases in which there was a change in diagnosis or treatment after the review of histological samples. There were 114 cases $(55.34 \%$ of the ileitis and $2.94 \%$ of the total) considered as clinically significant lesions, of these 79 were from control exams of patients with inflammatory bowel disease. The remaining cases are illustrated in TABLE 1.

Thus, considering the other indications, 35 exams out of 127 $(27.56 \%)$ were clinically relevant. The diagnosis found in the 35 cases of patients who did not have IBD were: 16 diagnostic exams of IBD, eight cases of graft versus host disease (GVHD), two ileitis due to cytomegalovirus, two carcinoid tumors, two ileitis related to spondyloarthropathy, one ileitis associated with vasculitis (Churg Strauss syndrome), one eosinophilic ileocolitis, one ileitis caused by Epstein-Barr virus, one drug-related ileitis (non-steroidal antiinflammatory) and one case of GVHD associated with cytomegalovirus infection.

An anatomopathologic review of 163 patients was performed, $79.13 \%$ of the total cases of ileitis (FIGURE 1). Some cases were excluded from the analisis: in six cases the biopsy material wasn't
TABLE 1. Indications for colonoscopies exams.

\begin{tabular}{lcc}
\hline Indication & $\begin{array}{c}\text { n } \\
\text { total }\end{array}$ & $\begin{array}{c}\text { n clinically } \\
\text { relevant }\end{array}$ \\
\hline Control of inflammatory bowel disease & 79 & 79 \\
Diarrhea & 16 & 11 \\
Bleeding & 15 & 6 \\
Screening & 16 & 2 \\
Abdominal pain & 10 & 2 \\
Polyp control & 14 & 2 \\
Anemia & 8 & 1 \\
Weight loss & 8 & 1 \\
Others & 10 & 3 \\
Anemia and weight loss & 1 & 1 \\
Abdominal pain, diarrhea and weight loss & 1 & 1 \\
Abdominal pain, bleeding and weight loss & 1 & 1 \\
Abdominal pain and others & 2 & 1 \\
Diarrhea and bleeding & 3 & 1 \\
Abdominal pain and bleeding & 3 & 1 \\
Diarrhea and others & 1 & 1 \\
Abdominal pain, diarrhea and others & 1 & - \\
Abdominal pain and diarrhea & 1 & - \\
Abdominal pain and polyp control & 1 & - \\
Abdominal pain and constipation & 1 & - \\
Abdominal pain, bleeding and constipation & 1 & - \\
Bleeding and weight loss & 2 & - \\
Bleeding and anemia & 1 & - \\
Anemia and diarrhea & 2 & - \\
Anemia and change in bowel habits & 1 & - \\
Constipation & 1 & - \\
Diarrhea and weight loss & 1 & - \\
Weight loss and change in bowel habits & 1 & - \\
Weight loss and others & 1 & - \\
Cancer control & 1 & - \\
Change in bowel habits & 2 & - \\
Total & & 114 \\
\hline
\end{tabular}

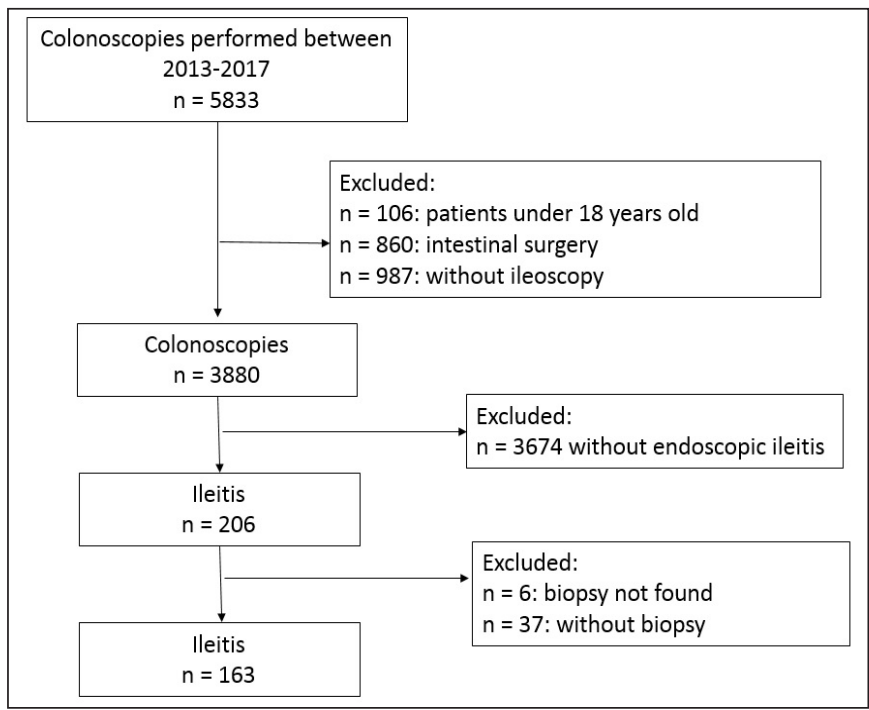

FIGURE 1. Description of the study sample, colonoscopies and biopsies included. 
found and in 37 cases no biopsies were performed at the time of the exam, of which 19 exams were for the control of patients with IBD and the others had characteristic macroscopy of lymphoid hyperplasia during colonoscopy.

The average age was $47 \pm 14.74$ years old (18-78 years old) and the gender distribution was mostly composed by women, 100 $(61.35 \%)$.

The macroscopic findings are shown in TABLE 2. TABLE 3 illustrates the microscopic findings found by pathologists.

TABLE 2. Macroscopic ileal findings with colonoscpy.

\begin{tabular}{ll}
\hline Lesion & $\mathrm{n}(\%)$ \\
\hline Erosion & $49(23.79)$ \\
Ulcer & $46(22.33)$ \\
Lymphoid hyperplasia & $32(15.53)$ \\
Others & $18(8.74)$ \\
Enanthema & $11(5.35)$ \\
Erosion and enanthema & $9(4.37)$ \\
Poplyp & $9(4.37)$ \\
Ulcer and erosion & $5(2.43)$ \\
Erosion and others & $6(2.92)$ \\
Enanthema and others & $3(1.46)$ \\
Ulcer, enanthema and others & $4(1.94)$ \\
Ulcer and lymphoid hyperplasia & $1(0.48)$ \\
Lymphoid hyperplasia and polyp & $1(0.48)$ \\
Ulcer e polyp & $2(0.97)$ \\
Lymphoid hyperplasia, erosion and enanthema & $2(0.97)$ \\
Erosion, enanthema and others & $2(0.97)$ \\
Ulcer and others & $4(1.94)$ \\
Ulcer and enanthema & $2(0.97)$ \\
Total & $206(100)$ \\
\hline
\end{tabular}

TABLE 3. Anatomopathological findings between the two pathologists.

\begin{tabular}{lcc}
\hline & Patologist 1 & $\begin{array}{c}\text { Pathologist expert in } \\
\text { gastrointestinal pathology }\end{array}$ \\
\hline Ulcer & 22 & 35 \\
Erosion & 24 & 52 \\
Viral inclusion & 2 & 4 \\
Acute ileitis & 49 & 63 \\
Chronic ileitis & 80 & 41 \\
Lymphoid hyperplasia & 33 & 57 \\
Normal ileum & 12 & 22 \\
Others & 61 & 34 \\
\hline
\end{tabular}

There was agreement between pathologists in $81(49.69 \%)$ cases and in $85(52.15 \%)$ cases there was agreement between the gastrointestinal pathologist and the endoscopist. In $48(29.45 \%)$ cases there was agreement between pathologists and endoscopist.

Evaluating the kappa index, a weak correlation was observed between pathologists (kappa 0.067) and between the gastrointestinal pathologist and the endoscopist (kappa 0.141). It should be noted that the disagreement between pathologists and endoscopists did not change, with clinical relevance, the management of patients studied, because gastroenterologists have taken into consideration both descriptions. TABLE 4 show the disagreement between pathologists and endoscopists.
TABLE 4. Agreement between macroscopic endoscopic findings, pathological findings and clinical relevance in slide review exams.

\begin{tabular}{lccc}
\hline $\begin{array}{l}\text { Endoscopic macroscopic } \\
\text { description }\end{array}$ & Endoscopy & $\begin{array}{c}\text { Pathological } \\
\text { agreement }\end{array}$ & $\begin{array}{c}\text { Clinical } \\
\text { relevance }\end{array}$ \\
\hline Erosion & 36 & 26 & 25 \\
Ulcer & 16 & 16 & 22 \\
Lymphoid hyperplasia & 12 & 5 & 4 \\
Others & 9 & 0 & 8 \\
Enanthema & 8 & 0 & 5 \\
Erosion and enanthema & 7 & 3 & 3 \\
Poplyp & 5 & 0 & 3 \\
Ulcer and erosion & 5 & 2 & 4 \\
Erosion and others & 2 & 0 & 2 \\
Erosion, enanthema and & & & \\
others & 4 & 0 & 2 \\
Ulcer, enanthema and & 3 & 1 & 3 \\
others & 3 & 0 & 3 \\
Ulcer and others & 2 & 1 & 2 \\
Enanthema and others & 1 & 0 & 0 \\
Ulcer e polyp & 2 & 0 & 0 \\
Lymphoid hyperplasia, & 1 & 0 & 1 \\
erosion and enanthema & & & \\
Ulcer and enanthema & & & \\
Ulcer and lymphoid & & & \\
hyperplasia & & & \\
Total & & & \\
\hline & & & \\
\hline
\end{tabular}

\section{DISCUSSION}

In the present study, ileal alterations were found in $5.31 \%$ of the exams. These data are similar to those reported in the literature, varying from $1-5^{0} 0^{(7,13-18)}$. Considering the total number of ileitis cases in this study, only $2.94 \%$ showed clinical relevance, indicating a diagnosis or a change of treatment. This finding was also concurrent with the literature, which reports that ileal examination helped in the diagnosis in $1.0-7.2 \%$ of routine colonoscopies ${ }^{(12,15,16,19-22)}$.

In this study, indications for colonoscopy with the highest number of ileitis and clinically significance were those performed in patients for control of IBD and those under investigation of chronic diarrhea. In 1998, in order to justify ileal examination in patients with IBD, Geboes retrospectively evaluated the ileoscopies of patients with IBD versus a control group demonstrating that 123 of the 257 patients with IBD had ileitis, while the control group had none ${ }^{(23)}$. In the same way, patients in investigation for chronic diarrhea have histopathological alterations in 9 to $19 \%$, according to the literature ${ }^{(24-28)}$.

There is a low correlation between pathologists, that can be explained by the peculiarities of an ileal evaluation, and by the fact that some gastrointestinal pathologists are more habituated to diagnose them than others ${ }^{(2,29)}$.

The most common ileal inflammatory lesion is acute nonspecific terminal ileitis, and in our results, only the gastrointestinal pathologist was able to identify this ${ }^{(14,20,29)}$. In chronic inflammation, the most prominent signs are architectural changes, alterations of the epithelial cells, as well as changes in the composition of the inflammatory infiltrate in the lamina propria ${ }^{(2,29)}$. 
The literature suggests that for the interpretation of ileal biopsies, pathologists should take a systematic approach, which could enable them to document all the changes in an organized manner and would help in the diagnosis ${ }^{(29)}$. The first step is to evaluate the mucosal changes and establish if there is chronic or acute inflammation. In our results, we saw that this differentiation was one of the biggest differences between pathologists, probably because only gastrointestinal pathologists are well trained with this systematization, and also because one sample can have both presentations, a diagnosis of "chronic ileitis with activity" ${ }^{(29)}$. The following steps for pathological findings and possible diagnosis depend on the first one, showing this as the most relevant differentiation in the ileal histopathological evaluation ${ }^{(29)}$.

It is well stablished that in ileal histopathological evaluation the presence of lymphocytes and plasma cells in intestinal mucosa is not indicative of pathological inflammation, it is physiological, and only if the composition and distribution of the inflammatory cells change, there is a pathological situation ${ }^{(2)}$. In our results, the number of normal ileum cases increased when analyzed by the gastrointestinal pathologist. The expert pathologist know that a diagnosis of normal histology does not exclude inflammatory or infectious disease, because in some pathological situations the mucosal alterations can be minimal, focal or even absent ${ }^{(2)}$.

Lymphoid tissue is normally found in the ileum and is therefore often undervalued by pathologists. In our study, the diagnosis of lymphoid hyperplasia was more frequently observed by the specialist, than the first general pathologist ${ }^{(2,29)}$.

It is possible to make a diagnosis of ileitis in biopsies, but etiology will often depend on additional clinical data ${ }^{(2)}$. Ileal biopsies should be analyzed with a detailed knowledge of the patient's clinical presentation, endoscopic, radiological and lab workup for optimal correlation $^{(2,29)}$. Our study is the first to have interobserver variability in ileal biopsies as its scope. We found that even though there is a high disagreement between specialist and general pathologists, this disagreement was not relevant in the conduction of the cases, because histology findings either did not change the outcome of the workup, or clinical and endoscopic data were sufficient to plan workup regardless of the biopsy findings.

Our study also showed that there is a low correlation between the pathologist and endoscopist. It is important to realize that some endoscopic alterations have no pathologic specific correlation, such as erythema or edema, as well as pathologic alterations, such as chronic and acute ileitis are sometimes not evident on endoscopy. The description of erosion and ulcer are the alterations with most disagreement between endoscopists and pathologists. This can be the result of sampling (erosions are sometimes difficult to properly sample), and also because they can have similar endoscopic appearances, but can be easily separated on histology.

\section{CONCLUSION}

This study had some limitations such as sample size, bias of the population studied (tertiary hospital sample), and retrospective design. However, unlike other studies that have been already published, our study analyses the difference between pathologists and endoscopists, showing that even if there is a low correlation, there is no compromise in patient follow-up.

Therefore, the study concludes that the association between pathologist, endoscopist, and clinical gastroenterologist is able to provide diagnosis and correct management of ileitis.

\section{Authors' contribution}

Rosevics L designed the research study, performed the research and wrote the paper. Ramos Júnior O designed the research study and wrote the paper. Kotze LR performed the research and wrote the paper.

\section{Orcid}

Leticia Rosevics: 0000-0001-7307-1895.

Luiz Roberto Kotze: 0000-0001-8456-4361.

Odery Ramos Júnior: 0000-0002-9730-6860.

Rosevics L, Kotze LR, Ramos Júnior O. Ileites - endoscopistas e patologistas falam a mesma língua? Arq Gastroenterol. 2021;58(2):145-9.

RESUMO - Contexto - Ileíte é definida como uma inflamação ileal, que pode ser avaliada durante a colonoscopia. Biópsias devem ser realizadas em íleos alterados, acrescentando na definição diagnóstica. Objetivo - Avaliar a correlação de achados anatomopatológicos das ileítes entre patologistas e endoscopistas. Métodos - Estudo retrospectivo, transversal, entre os anos de 2013 e 2017. Foram avaliados laudos de exames, indicações e prontuários para identificar quando os achados colonoscópicos foram significativos. As amostras de anatomopatologia foram revisadas por um patologista especialista em trato gastrointestinal. Foram incluídos pacientes acima de 18 anos, com ileoscopia, e excluídos pacientes menores de 18 anos e os com ressecções intestinais prévias. A correlação foi avaliada utilizando-se o coeficiente kappa. Resultados - Durante o período do estudo foram realizadas 5833 colonoscopias, das quais 3880 foram incluídas. Alterações ileais foram observadas em 206 casos, com 2,94\% sendo clinicamente significativo. Cento e sessenta e três biópsias foram avaliadas, resultando em coeficiente kappa entre patologistas de 0,067 e entre patologista e endoscopista de 0,141. Conclusão - Foi observado que a despeito da baixa concordância entre patologistas e endoscopistas, não houve mudança no desfecho clínico do paciente. Esse estudo confirma a importância do conhecimento dos achados anatomopatológicos principais das ileítes entre patologistas e endoscopias, fazendo o melhor diagnóstico e seguimento.

Palavras-chave - Colonoscopia; ileíte; doença inflamatória intestinal; patologia gastrointestinal. 


\section{REFERENCES}

1. DiLauro S, Crum-Cianflone NF. Ileitis: When It Is Not Crohn's Disease. Curr Gastroenterol Rep. 2010;12:249-58.

2. Cuvelier C, Demetter P, Mielants H, Veys EM, De Vos M. Interpretation of ileal biopsies: Morphological features in normal and diseased mucosa. Histopathology. 2001;38:1-12.

3. Borsotti E, Barberio B, D'Incà R, Bonitta G, Cavallaro F, Pastorelli L, et al. Terminal ileum ileoscopy and histology in patients undergoing high-definition colonoscopy with virtual chromoendoscopy for chronic nonbloody diarrhea: A prospective, multicenter study. United Eur Gastroenterol J. 2019;7:974-81

4. Neilson LJ, Bevan R, Panter S, Thomas-Gibson S, Rees CJ. Terminal ileal intubation and biopsy in routine colonoscopy practice. Expert Rev Gastroenterol Hepatol. 2015;9:567-74.

5. Geboes K. The strategy for biopsies of the terminal ileum should be evidence based. Am J Gastroenterol. 2007;102:1090-2.

6. Bojic D, Markovic S. Terminal ileitis is not always Crohn's disease. Ann Gastroenterol. 2011;24:271-5.

7. Emami MH, Behbahan IS, Zade HD, Daneshgar H. New interpretation for diagnostic yield of ileoscopy: A prospective study and a brief review. J Res Med Sci. 2009; 14:157-63.

8. Nagasako K, Yazawa C, Takemoto T. Biopsy of the terminal ileum. Gastrointest Endose 1972;19:7-10.

9. Sands BE. From symptom to diagnosis: Clinical distinctions among various forms of intestinal inflammation. Gastroenterology. 2004;126:1518-32.

10. Fujita K, Naganuma M, Saito E, Suzuki S, Araki A, Negi M, et al. Histologically confirmed IgG4-related small intestinal lesions diagnosed via double balloon enteroscopy. Dig Dis Sci. 2012;57:3303-6.

11. Hiyoshi Y, Oki E, Zaitsu Y, Ando K, Ito S, Saeki H, et al. IgG4-related disease of the ileocecal region mimicking malignancy: A case report. Int J Surg Case Rep. 2014;5:669-72.

12. Yoong KKY, Heymann T. It is not worthwhile to perform ileoscopy on all patients. Surg Endosc Other Interv Tech. 2006;20:809-11.

13. Akere A, Otegbayo J, Tejan E. Terminal ileum intubation during colonoscopy: Should it be routinely performed on all patients? Trop J Med Res. 2017;20:66.

14. Koksal AR, Boga S, Alkim H, Ergun M, Bayram M, Sakiz D, et al. How does a biopsy of endoscopically normal terminal ileum contribute to the diagnosis? which patients should undergo biopsy? Libyan J Med. 2014;9:1-8.

15. Cherian S, Singh P. Is routine ileoscopy useful? An observational study of procedure times, diagnostic yield, and learning curve. Am J Gastroenterol. 2004;99:2324-9.
16. Geboes K. Is Ileoscopy With Biopsy Worthwhile in Patients Presenting With Symptoms of Inflammatory Bowel Disease? Am J Gastroenterol. 1998;93:201-6.

17. Jeong SH, Lee KJ, Kim YB, Kwon HC, Sin SJ, Chung JY. Diagnostic value of terminal ileum intubation during colonoscopy. J Gastroenterol Hepatol. 2008;23:51-5

18. Wijewantha HS, De Silva AP, Niriella MA, Wijesinghe N, Waraketiya P, Kumarasena RS, et al. Usefulness of routine terminal ileoscopy and biopsy during colonoscopy in a tropical setting: A retrospective record-based study. Gastroenterol Res Pract. 2014;2014: 343849.

19. McHugh JB, Appelman HD, McKenna BJ. The diagnostic value of endoscopic terminal ileum biopsies. Am J Gastroenterol. 2007;102:1084-9.

20. Melton SD, Feagins LA, Saboorian MH, Genta RM. Ileal biopsy: Clinical indications, endoscopic and histopathologic findings in 10,000 patients. Dig Liver Dis. 2011;43:199-203.

21. Kundrotas LW, Clement DJ, Kubik CM, Robinson AB, Wolfe PA. A prospective evaluation of successful terminal ileum intubation during routine colonoscopy. Gastrointest Endosc. 1994;40:544-6.

22. Felice R. Zwas, Nelson A. Bonheim, Clifford A. Berker SG. Diagnostic yield of routine ileoscopy. Am J Gastroenterol. 1995;90:1441-3.

23. Kennedy G, Larson D, Wolff B, Winter D, Petersen B, Larson M. Routine ileal intubation during screening colonoscopy: A useful maneuver? Surg Endosc Other Interv Tech. 2008;22:2606-8.

24. Petre S, Shah IA, Gilani N. Review article: gastrointestinal amyloidosis - clinical features, diagnosis and therapy. Aliment Pharmacol Ther. 2008;27:1006-16.

25. Yusoff IF, Ormonde DG, Hoffman NE. Routine colonic mucosal biopsy and ileoscopy increases diagnostic yield in patients undergoing colonoscopy for diarrhea. J Gastroenterol Hepatol. 2002;17:276-80.

26. Marshall JB, Barthel JS. The frequency of total colonoscopy and terminal ileal intubation in the 1990s. Gastrointest Endosc. 1993;39:518-20.

27. Fine KD, Seidel RH, Do K. The prevalence, anatomic distribution, and diagnosis of colonic causes of chronic diarrhea. Gastrointest Endosc. 2000;51:318-26.

28. Hamid S, Jafri W, Abbas Z, Shah H, Abid S, Sheikh H, et al. Microscopic colitis: A diagnosis to consider. J Pak Med Assoc. 1993;43:203-5.

29. Das P, Gahlot GPS, Mehta R, Gupta SD. Interpretation of ileal biopsies Full Text Introduction Ileal Anatomy Technical Aspects of an Ileal Biopsy Inflammatory Conditions of Ileum. 2019:5-8. 